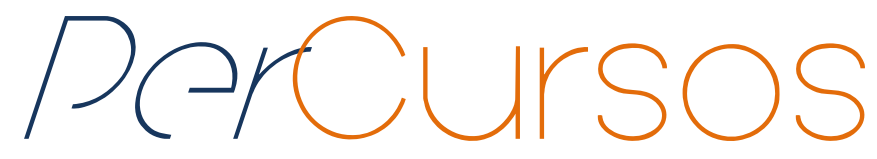

\title{
Um estudo comparativo dos processos de derivação prefixal e composição na gramática tradicional
}

\section{Resumo}

Este trabalho apresenta uma análise do processo de formação de palavras, baseada apenas nos processos de derivação prefixal e composição, examinando a controvérsia que existe nas gramáticas que ora tratam uma palavra como derivada ora como composta. Autores que estudam a morfologia da língua portuguesa têm observado que essa controvérsia ocorre especificamente em palavras prefixadas, que, em uma gramática, são tratadas como composição, mas, em outra, como derivação, e não veem perspectivas de mudança, porque as gramáticas tradicionais são cópias de gramáticas antigas e essa tradição dificulta a revisão e a adoção de novas posições. Além disso, a gramática tradicional é tomada como autoridade, por isso muitas vezes apenas apresenta uma lista de palavras sem explicá-las e omite aquilo para o que não tem explicação ou que questionaria a sua proposta de análise. Sendo assim, a possibilidade de mudanças na gramática tradicional é um vislumbre ainda que esses "prefixos", sincronicamente, tenham perdido sua significação e o falante da língua não reconheça, na palavra, duas unidades mínimas significativas. Esses aspectos são discutidos nesse trabalho, em que é feito um levantamento de dados em duas gramáticas tradicionais e discutidos à luz de estudos morfológicos atuais sobre derivação prefixal e composição, a fim de propor uma abordagem que contemple aspectos desconsiderados nas gramáticas tradicionais sobre esse tema.

Palavras-chave: Gramática. Composição. Derivação. Prefixação.
Leive de Queiroz Gianezi

Graduanda em Letras -

habilitação Português e Inglês na

Universidade Federal de Mato

Grosso do Sul - UFMS.

Brasil

leivedequeiroz@gmail.com

\section{Cleonice Candida Gomes}

Doutora em Linguística pela

Universidade de São Paulo - USP.

Professora da Univ. Federal de

Mato Grosso do Sul - UFMS.

Brasil

cleonicecgl@gmail.com

\section{Para citar este artigo:}

GIANEZI, Leive de Queiroz; GOMES, Cleonice Candida. Um estudo comparativo dos processos de derivação prefixal e composição na gramática tradicional. Revista PerCursos, Florianópolis, v. 18, n.37, p. 92 - 107, maio/ago. 2017.

\section{DOI: $10.5965 / 1984724618372017092$}

http://dx.doi.org/10.5965/1984724618372017092 


\title{
A comparetive study of the derivation prefixal processes and composition in traditional grammar
}

\begin{abstract}
This paper present an analysis of word formation process, based only in prefixal derivation processes and composition, examining the controversy in grammars that classify words either as a derivation or as compounding. Authors who study Portuguese morphology have observed that this controversy occurs specifically in prefixed words, that, in a grammar, are treated as composition, but, in other, as derivation, and there are not change perspectives yet, because traditional grammars are copies of old grammars and this tradition hinders the revision and adoption of new positions. Besides that, the traditional grammar is perceived as an authority, so often only presenting a list of words without explaining them and omits that for what does not have explanation or would question its analysis proposal. Therefore, possibility of change in traditional grammar is a glimpse even though these "prefixes", synchronously, lost their meaning and when using the language the speaker does not recognize, in one word, two significant minimum units. These aspects are discussed in this paper, in which a datae collection was performed in two traditional grammars. Discussed in the light of current morphological studies about prefixed derivation and composition, in order to propose an approach that considers disregarded aspects in traditional grammars about this subject.
\end{abstract}

Keywords: Grammar. Composition. Derivation. Prefixation. 


\section{Introdução}

Este trabalho discute a análise da prefixação apresentada nas gramáticas tradicionais. Tem como objetivo propor uma análise da prefixação, examinando a controvérsia que existe nas gramáticas que ora tratam uma palavra como derivação e ora como composição. Para isso, a metodologia baseou-se em um corpus de dados extraídos de duas gramáticas tradicionais, neste caso, "Nova gramática do português contemporâneo", de Cunha \& Cintra (2013) e "Moderna gramática portuguesa”, de Evanildo Bechara (2002), analisados à luz de Rocha (2008), verificando o que é considerado prefixação e composição e qual a abordagem dos autores sobre o assunto. Primeiramente, são apresentados os principais processos de formação de palavras. Em seguida, é discutido o processo de prefixação nas gramáticas tradicionais; e, por último, faz-se a análise de algumas palavras prefixadas.

\section{Processos de formação de palavras}

Existem os seguintes processos de formação de palavras na língua portuguesa: derivação, composição e onomatopeia.

A derivação é um processo de criação lexical que forma uma nova palavra por meio do acréscimo de um prefixo, de um sufixo ou de um prefixo e um sufixo simultaneamente a uma base já existente, tanto uma raiz quanto um radical.

A composição é um processo de formação de nova palavra por meio da junção de duas bases já existentes, sua estrutura fônica pode ou não mudar, dando origem a um novo significado. "Através desse processo combinam-se dois morfemas lexicais, operando-se entre eles uma fusão semântica, que pode ser mais ou menos completa" (KOCH; SILVA, 2001). A composição é um processo autônomo muito rico e diversificado na língua portuguesa. Na composição, a junção de dois léxicos distintos em apenas um elemento acaba por criar palavras compostas que se desvinculam do significado particular de cada componente. 
A onomatopeia é a palavra criada pelo falante ao tentar imitar um barulho ou um ruído do mundo exterior, por exemplo: miar, piar, zunzum, reco-reco, farfalhar, frufru, teco-teco, tique-taque, ciciar, etc.

Este trabalho tem como foco principal propor uma análise comparativa somente entre derivação prefixal e composição, portanto será feita uma breve conceituação no que se refere aos outros tipos de derivação.

\subsection{Tipos de derivação}

a) sufixal: é formada por um acréscimo de sufixos ao morfema lexical. Eles apresentam uma significação léxica, um valor geral e abstrato, como, por exemplo, alguns sufixos formam substantivos abstratos, outros formam adjetivos e há outros ainda que formam verbos.

b) prefixal e sufixal: nesse tipo de derivação são acrescidos tanto prefixos como sufixos ao morfema lexical.

c) parassintética: ocorre um acréscimo simultâneo de um prefixo e de um sufixo no morfema lexical, constituindo assim um morfema gramatical único e de caráter descontínuo. É mais utilizado no processo de formação de verbos e de alguns adjetivos. A função semântica fica atribuída ao prefixo e a função sintática cabe ao sufixo.

d) conversiva: implica no emprego de uma palavra de uma determinada classe lexical em outra classe; recebe também o nome de derivação imprópria.

e) siglada: nesse caso, a base será um substantivo ao mesmo tempo próprio e composto e o produto, um lexema simples e próprio, formado pelos grafemas e sílabas iniciais da base; as sigladas funcionam como palavras normais da língua.

f) truncada: procede de corte da palavra e, sob o ponto de vista fônico, resulta em um vocábulo menor. 
g) prefixal: a derivação prefixal é um processo que consiste em criar uma nova palavra por acréscimo de uma sequência fônica colocada à esquerda da base, e que não constitui uma base, mas apresenta uma identidade fonológica, semântica e funcional. Os prefixos se caracterizam por ser de forma presa. Existem pouco mais de cinquenta prefixos em língua portuguesa.

“Em português, raízes e radicais servem de base para a adjunção de afixos" (PETTER, 2003). A raiz é um elemento imutável e comum em todas as palavras derivadas; a raiz está incluída no radical.

Alguns exemplos de palavras por derivação prefixal:

$$
\begin{aligned}
& \operatorname{ler}_{\text {base }}>\text { re }_{\text {prefixo }}+\operatorname{ler}_{\text {base }}>\text { reler derivação prefixal } \\
& \text { por }_{\text {base }}>\text { inter }_{\text {prefixo }}+\text { por }_{\text {base }}>\text { interpor derivação prefixal }
\end{aligned}
$$

\subsection{Tipos de composição}

a) Composição por justaposição: na justaposição, elementos se juntam lado a lado, porém mantêm sua autonomia fonética, ou seja, os acentos e todos os fonemas que os constituem. A grafia pode ser com os vocábulos unidos ou separados, com ou sem hífen, como, por exemplo, passatempo, girassol, amor-perfeito. Em português, o primeiro elemento na composição serve de núcleo quando as estruturas são formadas por: substantivo + substantivo > sofá-cama, peixe-espada, mestre-sala; substantivo + adjetivo > caixa-alta, obra-prima, amor-perfeito; verbo + substantivo > guarda-roupa, portaestandarte, beija-flor. No caso de, na palavra composta, haver adjetivo, esse é sempre modificador (especificador), independente da posição em que se encontra na palavra, como no caso de belas-artes, livre-arbítrio. A palavra composta apresenta uma relação entre um núcleo e um modificador, entre um determinado e um determinante.

b) Composição por aglutinação: o vocábulo perde sua autonomia fonética, ou seja, ele se funde em um todo fonético, com um único acento, perdendo ou não algum de seus elementos: acento tônico, vogais ou consoantes. Têm-se alguns exemplos: plano + alto > planalto; ponta + agudo > pontiagudo; água + ardente > aguardente, entre outros. 
Porém, na análise mórfica, só se pode falar em aglutinação se o falante da língua tiver conhecimento dos dois morfemas lexicais. Desta forma, no caso de algumas palavras como agrícola (habitante do campo), fidalgo (filho de algo), aqueduto (condutor de água) só se pode falar em composição numa análise diacrônica.

De todos os processos apresentados até o momento, o trabalho verifica apenas a composição e a derivação prefixal, devido à falta de coerência no tratamento de algumas palavras nas gramáticas tradicionais que ora são abordadas como prefixadas, ora como compostas.

\section{Prefixação e composição na gramática tradicional}

Essa seção descreve o tratamento da derivação prefixal e da composição nas gramáticas de Cunha \& Cintra e de Bechara .

\subsection{Prefixação e composição por Cunha \& Cintra}

Inicialmente, Cunha \& Cintra, considerando a controvérsia existente na Língua Portuguesa sobre a que área pertence a Formação de Palavras, citam o seguinte conceito de Jean Dubois (DUBOIS, 1973 apud CUNHA; CINTRA 2013, p. 97):

Chama-se FORMAÇÃO DE PALAVRAS o conjunto de processos morfossintáticos que permitem a criação de unidades novas com base em morfemas lexicais. Utilizam-se assim, para formar as palavras, os afixos de derivação ou os processos de composição.

Então, Cunha \& Cintra estabelecem que a formação de palavras pode ocorrer por meio de derivação ou composição. No entanto, como nem sempre é fácil estabelecer a diferença entre elas, quando as palavras são formadas pelo uso de prefixos, os autores preferem considerar, tal formação, como derivação prefixal. “... os prefixos formam novas palavras que conservam de regra uma relação de sentido com o radical derivante" (CUNHA; CINTRA, 2013, p. 98). 
Os prefixos da língua portuguesa são de origem grega ou latina e em geral de advérbios ou de preposição, por isso são independentes, já que preposição e advérbio têm ou tiveram vida autônoma na língua portuguesa. Alguns, por exemplo, sofrem algumas alterações quando entram em contato com a vogal e com a consoante inicial da palavra que será derivada. Por exemplo, o prefixo grego an-, indicador de privação, assume a forma $a$ - antes de consoante: $a$-patia; o prefixo latino in- perde $0-n$ antes de $I$ ou m: i-legal, i-moral, enquanto com outras consoantes e com vogais ele permanece: infeliz, in-ativo.

Para Cunha \& Cintra, a composição se dá pela junção de dois ou mais radicais a fim de formar uma nova palavra. A palavra composta representa uma única ideia e tem autonomia em relação às bases, diferenciando assim os seus significados, na maioria das vezes.

A justaposição e a aglutinação estão relacionadas à forma da composição. Sendo que, na justaposição, cada qual conserva a sua integridade, como, por exemplo: beija-flor, madrepérola, pé-de-meia, etc. Na aglutinação, as palavras compostas "se subordinam a um único acento tônico e sofrem perda de sua integridade silábica" (CUNHA; CINTRA, 2013, p. 119), juntando-se em um só vocábulo, ficando, assim, água + ardente > aguardente; perna + alta > pernalta.

\subsection{Prefixação e composição por Bechara}

No que diz respeito ao sentido, a palavra composta possui o determinado e o determinante, sendo que o primeiro contém a ideia geral e o segundo determina noção particular. A ordem do determinado e determinante pode variar de acordo com o tipo de composição. Na composição de elementos da língua portuguesa, a ordem é determinado + determinante; na composição de elementos de origem latina, o determinante pode vir primeiro e o determinado depois.

Bechara (2002) aponta que, na prefixação, o radical recebe por empréstimo um elemento mórfico que dá à base uma nova significação e se relaciona semanticamente com preposições. Aparecem antes do radical e se agregam a verbos com mais frequência, 
a adjetivos em alguns casos e sua frequência em derivações do substantivo é menor em comparação às outras duas classes mencionadas. O autor esclarece ainda que os prefixos têm mais força significativa, têm existência independente na língua e não determinam uma nova classe gramatical para a palavra formada a partir dele.

De acordo com o autor, a composição se dá pela junção de dois radicais livres ou presos, resultando em um significado para o conjunto.

A composição é por justaposição quando as palavras são compostas com radicais livres, devido à individualidade de seus componentes; na escrita, quando separadas por hífen; na pronúncia, por não perderem sua tonicidade, cada radical mantém o seu acento tônico, "sendo o último o mais forte e o que nos orienta na classificação do acento nas palavras compostas (por isso que couve-flor é oxítono e guarda-chuva é paroxítono)." (BECHARA, 2002, p. 340).

Chama-se aglutinação quando a composição se dá pela fusão ou maior integração dos dois radicais, ocorrendo a perda da delimitação vocabular decorrente; na palavra composta, passa a existir apenas um acento tônico, há uma troca ou uma perda fonética, há modificação de ordem mórfica.

Na primeira palavra das palavras compostas pode haver adaptações como, por exemplo:

- mudança na parte final da palavra em relação à palavra isolada;

- em seu elemento radical, ocorrer uma redução;

- seu elemento radical ser alterado em relação à palavra isolada;

- o seu elemento radical não aparece em língua portuguesa em palavra isolada.

Na segunda palavra podem ocorrer as seguintes mudanças:

- mudança na parte final da palavra;

- alteração do elemento radical;

- elemento radical diverso do que corresponde à palavra isolada. 
“Na língua literária e técnica prefere-se empregar o radical de forma latina a utilizar o de forma vernácula, principalmente quando este já sofreu a evolução fonética" (BECHARA, 2002, p. 340-341). Emprega-se silvicultura ao invés de selvicultura, viticultura e não vidicultura, áureo, capilar, etc.

\section{Prefixação e composição - outras abordagens}

Após estabelecer tais conceitos, será apresentada a abordagem de Rocha (2008) e elencados alguns problemas e esclarecimentos referentes à prefixação.

\subsection{Prefixação: derivação ou composição?}

Para responder a essa pergunta, o autor esclarece que se deve analisar a palavra proposta e verificar se ela é formada por BASE + BASE e se possui a mesma função quando comparada separadamente, a fim de obter uma palavra composta.

Para verificar se se trata de derivação, a palavra deve apresentar a estrutura PREFIXO + BASE:

$$
\begin{aligned}
& {\left[\text { re-prefixo }[\text { ler }]_{V}\right]_{V}} \\
& {\left[\text { in- }{ }_{\text {prefixo }}[\text { feliz }]_{A}\right]_{A}} \\
& {\left[\text { de-prefixo }[\text { compor }]_{V}\right]_{V}}
\end{aligned}
$$

Rocha destaca ainda que palavras como "sobreviver", “conviver”, “entressafra” e “contradizer" fazem parte do processo de derivação prefixal, da que se encontra prefixo + base, porém Câmara Jr. (1964a, apud ROCHA, 2008, p. 148) discorda dessa afirmação pelo fato de que os elementos sobre, com, entre e contra possuem autonomia na língua portuguesa, por isso ele alega que as palavras dadas como exemplo devem ser consideradas como composição e não derivação prefixal.

Rocha (2008) esclarece e apresenta dois argumentos para comprovar o porquê de essas palavras serem consideradas derivação e não composição. 
Primeiro, uma palavra para fazer parte do processo de composição precisa ser base, já que composição se dá por BASE + BASE; precisa apresentar raiz, desse modo sobre, com, entre e contra não possuem raiz. Veja os exemplos apresentados por Rocha (2008):

a) Ela não pode conviver com os pais.

b) Ele sobrevive andando sobre as águas.

Assim sendo, segundo Rocha (2008), as entradas lexicais con- (forma presa) e com (forma dependente) assumem funções distintas e são itens lexicais diferentes, o mesmo acontece em sobre- e sobre. Os dicionários os registram em separado, mais uma prova de que são distintos um do outro.

\subsection{Base presa x prefixo}

Outra questão proposta é a dificuldade de se diferenciar base presa de prefixo. 0 que as gramáticas chamam de radicais, Rocha (2008) e alguns outros autores chamam de base presa.

Nas palavras compostas, a estrutura é de BASE + BASE (como já se sabe), ou seja, as raízes apresentam significação externa inequívoca. As bases presas, ainda que necessitem de outra palavra para se configurarem, possuem uma significação própria, equivalendo-se a substantivos, adjetivos ou verbos. Os prefixos, por sua vez, não apresentam raiz e são equivalentes a advérbios e preposições.

\subsection{Sincronia x diacronia}

Os prefixos são divididos em prefixos gregos e latinos, de acordo com as gramáticas tradicionais. Segundo Rocha (2008), para um estudo sincrônico, não há necessidade de tal divisão, porque essa divisão é uma herança da gramática tradicional, ou seja, isso faz parte do estudo diacrônico, o que para o falante não tem importância. No ponto de vista sincrônico, os vocábulos podem ser apresentados em grupos distintos por se tratar de prefixos populares ou eruditos, produtivos ou improdutivos, etc. Porém, a 
sincronia deixa a desejar, por falta de critérios quando se precisa definir se certa palavra é do português por meio de determinado processo. Somente um estudo diacrônico seria capaz de revelar se uma palavra como "sílaba”, "biscoito”, “objeto”, entre outras são formadas por derivação prefixal. Numa abordagem sincrônica, essas palavras seriam consideradas primitivas na língua portuguesa; ao passo que, numa abordagem diacrônica, seriam consideradas derivadas.

\subsection{Prefixação e mudança de classe}

A prefixação, em regra geral, não estabelece mudança de classe gramatical; isso é mais comum ao sufixo. São raras as formações do português em que acontece a transposição lexical por acréscimo de prefixo, no entanto nos exemplos $\left[\text { anti }_{\text {prefixo }}[\text { poluição }]_{\text {subst. }}\right]_{\text {adj. }}$, [anti prefixo $\left.\left._{\text {pulgas }}\right]_{\text {subst. }}\right]_{\text {adj., }}$ anti- funciona como adjetivo mas não assume todas as características dos adjetivos. O neologismo não concorda com o substantivo; trata-se de adjetivação precária, conforme Basílio (1987, apud ROCHA, 2008, p. 155). Encontra-se esse fenômeno também na derivação conversiva.

\subsection{Prefixação com base livre}

A base livre é a palavra que funciona como uma palavra na língua. Esse tipo de formação prefixal é muito produtiva, favorecendo, assim, o aparecimento de inúmeros casos de derivação com transparência morfológica e semântica da base livre.

\subsection{Prefixação com basóide}

Na prefixação por basóide, não se pode isolar a base, porém o prefixo pode ser isolado. A base não possui outro tipo formação. Por exemplo:

$\begin{array}{llcr}\text { dissidente } & \text { demolir } & \text { intruso } & \text { periferia } \\ \text { corroborar } & \text { impedir } & \text { trasladar } & \text { epitáfio }\end{array}$


Nesses casos, não se pode isolar a base, mas o prefixo sim, em dissidente, dis- é recorrente e aparece em outros vocábulos, como em: distender, dissolver, dilacerar, disjungir, etc. Já em corroborar o mesmo prefixo aparece em compor, conter, colaborar, etc. dando sentido de companhia, contiguidade. O prefixo de- em demolir é encontrado em declive, declinar, derrubar, debruçar, depor no sentido de por em movimento de cima para baixo.

No restante dos exemplos, pode-se perceber os prefixos im- e in- no sentido de negação, tras- dando sentido de movimento para além de, peri- com sentido de posição ou movimento em torno e epi- indicando posição superior.

É necessário observar que as basóides só existem na língua em função de um determinado prefixo. A -sidente só se junta o prefixo dis-, a -roborar só se junta o prefixo co-, e assim por diante. Em vista disso, podemos dizer que as basóides, como o nome está dizendo, não são bases verdadeiras, uma vez que uma característica fundamental da base, como vimos anteriormente, é que ela dever ser recorrente. Ora, como vimos, sidente, -roborar, -molir, -pedir, etc. não são elementos recorrentes da língua. (ROCHA, 2008, p. 160)

A basóide é considerada uma base vazia, por não possuir significação própria sem o prefixo, ou seja, só há significado se a base estiver com o devido prefixo. Desse modo, em dissente, se tirar o prefixo dis- da palavra, a base perde o seu significado.

\subsection{Prefixóides}

Os prefixos são de modo geral recorrentes, porém, existem alguns que não o são, conhecidos por prefixóides. São prefixos falsos, irrecorrentes.

Temos como exemplo de prefixóides: obter, contracenar, supor, resguardar, descrever, manter. Em todas essas formações os prefixóides dão um sentido único e exclusivo à base que não é encontrado em outro prefixo da língua portuguesa. Outro ponto importante é que todas as bases nesse tipo de derivação são livres. 


\subsection{Prefixos homófonos}

São prefixos homófonos todos aqueles que apresentam uma mesma identidade fonológica, porém a significação é distinta em cada palavra; não são, portanto, o mesmo prefixo em formações diferentes, são prefixos diferentes.

Alguns exemplos apresentados por Rocha (2008): reler, o prefixo re- dá ideia de repetição; em retrair, indica movimento para trás; e em reagir, o sentido é de movimento contrário. Percebe-se, então, prefixação com significados diferentes.

\section{Discussão do problema}

Comparando-se as palavras visconde, hipermercado, arcanjo, antebraço, hipotensão, telejornal, caligrafia, eufonia, bianual, anfiteatro, ambidestro, sublocar na gramática tradicional, representada por Bechara (2002) e por Cunha \& Cintra (2013), ao proposto por Rocha (2008) tem-se a seguinte tabela:

\begin{tabular}{|l|l|l|l|}
\hline PALAVRAS & \multicolumn{2}{|c|}{ GRAMÁTICA TRADICIONAL } & \\
\hline & CUNHA \& CINTRA & BECHARA & ROCHA \\
\hline Hisconde & Prefixação & Prefixação & $\begin{array}{l}\text { Composição: } \\
\text { vis/vice: base presa substantiva } \\
\text { conde: base livre substantiva }\end{array}$ \\
\hline Arcanjo & Prefixação & Prefixação & $\begin{array}{l}\text { Composição: } \\
\text { hiper: base presa adjetiva } \\
\text { mercado: base livre substantiva }\end{array}$ \\
\hline Antebraço & Prefixação & Prefixação & $\begin{array}{l}\text { Composição: } \\
\text { arc/arque: base presa adjetiva } \\
\text { anjo: base livre substantiva }\end{array}$ \\
\hline Hipotensão & Prefixação & Prefixação & $\begin{array}{l}\text { Composição: } \\
\text { ante: base presa substantiva } \\
\text { braço: base livre substantiva }\end{array}$ \\
\hline
\end{tabular}




\begin{tabular}{|c|c|c|c|}
\hline & & & $\begin{array}{l}\text { hipo: base presa adjetiva } \\
\text { tensão: base livre substantiva }\end{array}$ \\
\hline Telejornal & & Prefixação $^{1}$ & $\begin{array}{l}\text { Composição: } \\
\text { tele: base presa adjetiva } \\
\text { jornal: base livre substantiva }\end{array}$ \\
\hline Caligrafia & Composição & Composição & $\begin{array}{l}\text { Composição: } \\
\text { cali: base presa adjetiva } \\
\text { grafia: base livre substantiva }\end{array}$ \\
\hline Eufonia & Prefixação & Prefixação & $\begin{array}{l}\text { Composição: } \\
\text { eu: base presa adjetiva } \\
\text { conde: base livre substantiva }\end{array}$ \\
\hline Bianual & Composição $^{2}$ & Prefixação & $\begin{array}{l}\text { Composição: } \\
\text { bi: base presa adjetiva } \\
\text { anual: base livre adjetiva }\end{array}$ \\
\hline Anfiteatro & Prefixação & Prefixação & $\begin{array}{l}\text { Composição: } \\
\text { anfi: base presa adjetiva } \\
\text { teatro: base livre substantiva }\end{array}$ \\
\hline Ambidestro & Composição & Prefixação & $\begin{array}{l}\text { Composição: } \\
\text { ambi: base presa adjetiva } \\
\text { destro: base livre adjetiva }\end{array}$ \\
\hline Sublocar & Prefixação & Prefixação & $\begin{array}{l}\text { Composição: } \\
\text { sub: base presa adjetiva } \\
\text { locar: base livre verbal }\end{array}$ \\
\hline
\end{tabular}

Dada a tabela, percebe-se que, são consideradas derivadas por prefixação nas gramáticas de Cunha \& Cintra (2013) e Bechara (2002) as palavras: visconde, hipermercado, arcanjo, antebraço, hipotensão, eufonia, anfiteatro e sublocar, enquanto

\footnotetext{
${ }^{1}$ A palavra telejornal não aparece em Cunha \& Cintra (2013) e, também, não aparece em Bechara (2002, p. 369), mas, aparece como base, na citação de Bechara a respeito das palavras telégrafo, telepatia, teleguiado, sendo possível depreender que "telejornal" receba a mesma classificação das demais, de derivação prefixal.

${ }^{2}$ A palavra bianual não aparece em Cunha \& Cintra (2008), o elemento bi aparece como exemplo de radical. Para Rocha, um radical serve como base para compor uma palavra; desse modo, observa-se que, em Cunha \& Cintra, palavras com bi sejam consideradas como composição.
} 
Rocha (2008) considera-as como composição. A palavra caligrafia é considerada composição em Cunha \& Cintra (2013), em Bechara (2002) e em Rocha (2008). Bianual é tratada como prefixação por Bechara e por Rocha, já em Cunha \& Cintra essa palavra não é dada como exemplo e o elemento bi aparece como de radical. Para Rocha, um radical serve como base para compor uma palavra, desse modo, observa-se que, em Cunha \& Cintra, palavras com bi sejam consideradas como composição. A palavra telejornal não aparece em Cunha \& Cintra (2013) e, também, não aparece em Bechara (2002, p. 369), mas, aparece como base, na citação de Bechara a respeito das palavras telégrafo, telepatia, teleguiado, sendo possível depreender que "telejornal" receba a mesma classificação das demais, de derivação prefixal. A palavra ambidestro é considerada composição em Bechara (2002) e em Rocha (2008).

Essas diferenças emergem, porque os autores trabalham com critérios distintos para a análise da derivação prefixal ou da composição: a Gramática tradicional (GT) trata como prefixo ao que Rocha percebe como base presa; a GT dá ao assunto um tratamento diacrônico ao que Rocha faz uma abordagem sincrônica, considerando que, à maneira Saussuriana, somente a sincronia importa para o falante da língua; e, a GT não considera que, se a derivação sufixal desencadeia mudança de classe gramatical, isso deveria ocorrer também com a derivação prefixal, no entanto, isso não se dá, enquanto Rocha considera esse aspecto.

\section{Considerações finais}

Considerando o que foi exposto, foi possível verificar que as palavras analisadas no quadro são consideradas como derivação prefixal pelas gramáticas tradicionais por serem originadas de advérbios ou preposições que têm ou tiveram vida autônoma na língua. Contudo, Rocha (2008) nos apresenta que essas palavras são formadas pelo processo de composição, porque possuem duas raízes em seus elementos formadores com significação externa de maneira clara e inequívoca.

Outro aspecto que embasa a análise de Rocha (2008) é o fato de que apenas a derivação desencadeia mudança de classe gramatical: isso ocorre com a sufixação, no 
entanto, não ocorre com a prefixação. Logo, sufixação é um processo de derivação, mas a prefixação é um processo de composição.

Em linguística, baseando-se na visão Saussuriana, a perspectiva é que cria o objeto. Por isso, não se invalida nenhuma das análises, mas, para o ensino-aprendizagem, o professor deve ter claras as duas perspectivas e, de preferência, optar por partir de uma abordagem sincrônica, porque o estudante tem ciência de sua língua num momento específico rumo a uma abordagem diacrônica presente na GT.

\section{Referências}

BECHARA, Evanildo. Moderna gramática portuguesa. $37^{\mathrm{a}}$ ed. rev. e ampl., $12^{\mathrm{a}}$ Reimpressão - Rio de Janeiro: Editora Lucena, 2002, p. 351-380.

CUNHA, Celso; CINTRA, Lindley. Nova gramática do português contemporâneo. $6^{\mathrm{a}}$ ed. Rio de Janeiro: Lexicon, 2013, p. 97-132.

KOCH, Ingedore Villaça; SILVA; Maria Cecília Pérez de Souza e. Linguística aplicada ao português: morfologia. 12 ed. São Paulo: Cortez Editora, 2001, p. 31-34.

PETTER, Margarida Maria Taddoni. “Morfologia”. In: FIORIN, José Luís (Org.). Introdução à linguística II: princípios de análise. $5^{\text {a }}$ ed., $1^{\mathrm{a}}$ reimpressão - São Paulo: Contexto, 2012, p. 71-73

ROCHA, Luiz Carlos de Assis. Processos de formação de palavras. A derivação prefixal. In: ROCHA, Luiz Carlos de Assis. Estruturas morfológicas do português. $2^{a}$ ed. São Paulo: Wmf Martins Fontes. 2008, p. 147-163. 